\title{
Article
}

\section{Assessment of avoidance behaviour by earthworms (Lumbricus rubellus and Octolasion cyaneum) in laboratory-based linear pollution gradients.}

Lowe, Christopher Nathan, Butt, Kevin Richard and Cheynier, Kevin Yves-Marie

Available at http://clok.uclan.ac.uk/12716/

Lowe, Christopher Nathan ORCID: 0000-0002-3893-7371, Butt, Kevin Richard ORCID: 0000-0003-0886-7795 and Cheynier, Kevin Yves-Marie (2015)

Assessment of avoidance behaviour by earthworms (Lumbricus rubellus and Octolasion cyaneum) in laboratory-based linear pollution gradients. Ecotoxicology and Environmental Safety, 124 . pp. 324-328. ISSN 0147-6513

It is advisable to refer to the publisher's version if you intend to cite from the work. http://dx.doi.org/10.1016/j.ecoenv.2015.11.015

For more information about UCLan's research in this area go to http://www.uclan.ac.uk/researchgroups/ and search for <name of research Group>.

For information about Research generally at UCLan please go to http://www.uclan.ac.uk/research/

All outputs in CLoK are protected by Intellectual Property Rights law, including Copyright law. Copyright, IPR and Moral Rights for the works on this site are retained by the individual authors and/or other copyright owners. Terms and conditions for use of this material are defined in the policies page. 
1 Assessment of avoidance behaviour by earthworms (Lumbricus rubellus and Octolasion cyaneum) in

2 linear pollution gradients.

Christopher N. Lowe*, Kevin R. Butt, Kevin Yves-Marie Cheynier

5

6 School of Forensic and Applied Sciences, University of Central Lancashire, Preston, PR1 2HE, UK.

7 * Corresponding Author. Email address: cnlowe@uclan.ac.uk

Abstract

Avoidance behaviour by earthworms is recognised as a valuable endpoint in soil quality assessment and has resulted in the development of a standardised test (ISO 17512-1: 2008) providing epigeic earthworms with a choice between test and control soils. This study sought to develop and evaluate an avoidance test utilising soil-dwelling earthworms in linear pollution gradients with Visible Implant Elastomer (VIE) tags used to identify individual organisms. Sequential experiments were established in laboratory-based mesocosms $(0.6 \mathrm{~m} \times 0.13 \mathrm{~m} \times 0.1 \mathrm{~m})$ that determined the relative sensitivities (in terms of associated avoidance behaviour) of Octolasion cyaneum and Lumbricus rubellus at varying levels of polluted soil and also assessed the influence of introduction point on recorded movement within gradients. In an initial gradient $(0,25,50,75,100 \%$ polluted soil), both species exhibited a clear avoidance response with all surviving earthworms retrieved (after 7 days) from the unpolluted soil. In a less polluted gradient $(0,6.25,12.5,18.75,25 \%)$ L. rubellus were retrieved throughout the gradient while $O$. cyaneum were located within the 0 and $6.25 \%$ divisions, suggesting a species-specific response to polluted soil. Results also showed that the use of a linear pollution gradient system has the potential to assess earthworm avoidance behaviour and could provide a more ecologically relevant alternative to the ISO 17512: 2008 avoidance test. However, further work is required to establish the effectiveness of this procedure, specifically in initial chemical screening and assessment of single contaminant bioavailability, where uptake of pollutants by earthworms could be measured and directly related to the point of introduction and retrieval.

Keywords

Pollution gradient; avoidance test; earthworm tagging; visible implant elastomer

\subsection{Introduction}

Selection of organisms to assess pollution is based on critical factors including ecological relevance, ecological importance and sensitivity of the species (Smith et al., 2006). In a soil context, earthworms are considered particularly relevant test organisms as they form a significant component of the soil biomass, are constantly in intimate contact with the soil medium and due to their influence on soil physical, chemical and biological properties are considered ecosystem engineers (Jones et al., 1994; 
Jouquet et al., 2006). In addition to the well-established role of earthworms in standardised acute toxicity testing of chemicals, the relative resistance to pollutants of some species allows for sub-lethal measures of exposure to pollution. Bioassays have been undertaken utilising ecologically relevant sublethal endpoints including biomass, reproduction, casting and burrowing activity. For example, Dittbrenner et al. (2010) demonstrated significant losses in biomass for Lumbricus terrestris and Aporrectodea caliginosa at 1 and 3 times the recommended application dose $(0.66 \mathrm{ppm})$ of imidacloprid (insecticide) and Capowiez et al. (2010) recorded a significant decrease in casting activity of $L$. terrestris at the recommended dose.

Avoidance has also been recognised as a valuable endpoint for pollution assessment (Hund-Rinke et al., 2003) and for some chemicals, it may be as sensitive as reproduction (van Gestel, 2012). However, the relationship between avoidance and metal uptake/toxicity is unclear and the question of whether avoidance is triggered by a detrimental effect of pollutant uptake or by a sensory-based reaction (earthworms possess chemical receptors in the prostomium) remains unanswered (Ma and Bonten, 2011). Field assessment of the potentially complex interactions involved in earthworm behavioural responses to soil pollutants is difficult, due to their predominantly subterranean location and potential absence of precise knowledge of pollutants and their concentrations in the environment. Therefore, controlled laboratory-based experiments are recognised as a valuable step to assist understanding of these processes. An ISO standard (ISO 17512-1: 2008) provides earthworms (Eisenia fetida or Eisenia andrei) with a choice between a test soil and a control soil (Fründ et al., 2011). This standard details methods for both a two-section and a six-section avoidance test. The former has been employed by a number of researchers (e.g. Garcia et al., 2008; Owojori and Reinecke, 2009), but the latter has not been widely adopted, which may be related to practical considerations in creation of the circular, 6chambered experimental vessels. In two-section avoidance tests, earthworms are introduced into the centre of the vessel and after a fixed time period ( $48 \mathrm{~h}$ ) the number of earthworms present in each side is recorded and avoidance behaviour considered significant when more than $80 \%$ are located in the reference substrate. Avoidance has also been determined by measuring the number of earthworms which burrowed into a substrate after a fixed time period (Ma and Bonten, 2011).

Compared with other standardised sub-lethal tests (e.g. reproduction), avoidance tests are rapid, inexpensive and simple to perform, but the behavioural response is species- and chemical-specific and may be influenced by other soil properties (Naidu et al., 2008). For example, in two-section avoidance tests of soil spiked with Cu and Zn, Dendrobaena octaedra, Aporrectodea tuberculata and Lumbricus rubellus demonstrated a significant avoidance response in 48/80, 120/200 and 300/500 mg of Cu/Zn per $\mathrm{kg}$ of soil respectively (Lukkari and Haimi, 2005). The influence of pollution on earthworm movement has also been assessed using burrow length, topology and sinuosity in 2 dimensional terraria (often referred to as Evans' Boxes (Evans, 1947)) with daily mapping of burrow creation (Bolton and Phillipson, 1976) and 3 dimensional terraria with burrow measurements recorded at the end of the experiment using X-ray tomography (Bastardie et al., 2003). However, these tests bear little resemblance to the often heterogeneous nature of pollution and, with respect to $2 \mathrm{D}$ terraria, have limited ecological relevance to field conditions. Fründ et al. (2011) suggested that 3D terraria should be employed, containing a range of pollutant levels (gradients) as a proposed improvement to existing laboratory-based avoidance tests. A further issue, in both laboratory and field-based studies, which has restricted experimental design is the lack of a reliable method for identifying individual earthworms. However, a method of semi-permanently marking individual earthworms with Visible Implant Elastomer (VIE) tags has been demonstrated (Butt et al., 2009; Butt and Grigoropoulou, 2010; 
Butt and Lowe, 2007; González et al., 2006). Under controlled laboratory conditions, Butt and Lowe (2007) maintained tagged $L$. terrestris over a 12 month period and demonstrated that the tagging process did not affect growth, reproduction or fecundity. Silicon-based VIE tags are injected as a liquid under translucent tissue, before curing to a pliable solid, with tag colour selected to contrast earthworm pigmentation. Tags are also fluorescent, so can be located under blue light.

It has been recognised that earthworm species selection can have a significant influence on the outcome of ecotoxicological tests (reviewed by Lowe and Butt, 2007). The epigeic species E. fetida has been widely used in acute toxicity tests (mainly due to its ease of culture) and has also been adopted for use in chronic toxicity studies including the ISO 17512-1 avoidance test (ISO, 2008). However, the ecological relevance of this species, especially in studies utilising sub-lethal end points, is becoming more widely questioned (Lowe and Butt, 2007; Lukkari and Haimi, 2005; Svendsen et al., 2005). This is particularly relevant in assessing soil quality, as E. fetida is not found within the soil profile, is uncommon except in anthropogenic settings and is more tolerant to contaminants than many other species (Lukkari et al., 2005). A number of ecotoxicological studies have employed L. rubellus as a test species (e.g. Morgan and Morgan, 1999; Langdon et al., 2003; Spurgeon et al., 2004). Although L. rubellus is considered to be an epigeic species, it does venture into mineral soil and is present in the natural environment. Lowe and Butt (2007) have also suggested that mode of reproduction should be considered in species selection and have advocated the use of parthenogenetic species (e.g. Octolasion cyaenum) to reduce the influence of genetic drift.

The main aim of this research was to build on the recommendations of Fründ et al. (2011) by assessing the viability of utilising linear pollution gradients in combination with VIE tagging and the use of soil dwelling earthworm species in the development of a more ecologically relevant and practical avoidance test of soil quality. Sequential experiments were established in laboratory-based mesocosms to determine the relative sensitivities (in terms of associated avoidance behaviour) of $O$. cyaneum (endoge) and L. rubellus (epige) to varying levels of field-collected, polluted soil and to determine the influence of introduction point on recorded movement within gradients.

\subsection{Methods}

Polluted soil was collected from a derelict scrap metal depot in Preston, Lancashire $\left(53^{\circ} 45^{\prime} \mathrm{N} 2^{\circ} 43\right.$ 'W; the soil is considered artificial "made ground", $\mathrm{pH} 7.6$, organic matter $14 \%$ ). The site is contaminated with oil, PCBs and heavy metals. In a previous study (Glover, 2010) soil from the site was analysed using a Thermo Electron X5 Inductively Coupled Plasma Mass Spectrometer (ICP-MS) and recorded total metal soil concentrations for arsenic (75 ppm), copper (6617 ppm), chromium (403 ppm) and lead (33590 ppm); all above current UK Soil Guideline Value thresholds (Environment Agency, 2008). A survey at the site of soil collection recorded no earthworms. Collected soil was transferred to the laboratory where it was heated to $75^{\circ} \mathrm{C}$ for 45 minutes (in a Camplex Soil Steriliser) to kill living material, then homogenised by thorough mixing and passage through a $2 \mathrm{~mm}$ sieve. Experimental soil gradients were formed by blending proportions of the polluted soil with a presterilised and sieved Kettering Loam soil ( $\mathrm{pH}$ 7.2, organic content 5\%) obtained from Boughton Loam Ltd, Kettering, UK - a soil widely used in earthworm culture and laboratory-based studies (Lowe and Butt, 2005). Dried horse manure ( $2 \mathrm{~g}$ per $100 \mathrm{~g}$ of soil) was incorporated into each soil blend as a feed source and the substrate rewetted to a moisture content of approximately $25 \%$ (Lowe and Butt, 2005). 
Mature (clitellate) individuals of $L$. rubellus and O.cyaneum were field-collected by digging and handsorting soil in pasture at Cuerden Valley Park ( $53^{\circ} 42^{\prime} \mathrm{N} 2^{\circ} 39^{\prime} \mathrm{W}$; clayey loam soil) and in a tree plantation at Bank Hall ( $53^{\circ} 40^{\prime} \mathrm{N} 2^{\circ} 48^{\prime} \mathrm{W}$; silty-clay loam soil) respectively. Prior to experimental use, these earthworms were maintained in laboratory cultures as described by Lowe and Butt (2005).

Three gradient experiments were conducted using opaque plastic containers ( $0.6 \mathrm{~m} \times 0.13 \mathrm{~m} \times 0.1 \mathrm{~m})$ filled to a depth of $0.075 \mathrm{~m}$ with soil. Each experiment employed five levels of polluted soil, initially separated by plastic spacers (cut precisely to the dimensions of the containers section), resulting in five, $0.12 \mathrm{~m}$ soil divisions in a prescribed pollution gradient. To encourage earthworm burrowing activity within the soil profile, organic matter (horse manure) was not placed on the soil surface. After earthworm introduction, the spacers were removed and the containers covered with plastic (cling film), pierced with a mounted needle to allow ventilation and kept in $24 \mathrm{~h}$ darkness in a temperaturecontrolled incubator at $15{ }^{\circ} \mathrm{C}$. After 7 days, the spacers were re-inserted and earthworm positions within gradients established by destructive sampling. Any earthworm cut by a spacer was recorded as half retrieved from each section adjacent to the given spacer.

\subsection{Gradient 1: 0 to $100 \%$ (Introduction point at 100\%)}

This initial experiment had a pollution gradient ranging from 0 to $100 \%$ of polluted soil (with divisions of $0,25,50,75$ and $100 \%$ ). The divisions were arranged in order of pollution level, from the least to the most polluted. In each of five replicated containers, one mature $O$. cyaneum and one mature $L$. rubellus were introduced on to the soil surface in the centre of the $100 \%$ polluted soil division.

\subsection{Gradient 2: 0 to $25 \%$ (Introduction point at 25\%)}

In response to results obtained from Gradient 1 , a subsequent, reduced pollution gradient was established equating to sub-divisions of 0 to $25 \%$ of polluted soil $(0,6.25,12.5,18.75$ and $25 \%)$. The containers were constructed as for Gradient 1 and again, a single mature individual of each species was introduced on to the soil surface, but here at the centre of the $25 \%$ polluted soil division. Once again this set up was replicated 5 times and maintained under the same environmental conditions as previously described.

\subsection{Gradient 3: 0 to $25 \%$ (introduction points at 0\%, $12.5 \%$ and 25\%)}

Here, a mature $L$. rubellus and a mature 0 . cyaneum were introduced at 3 selected points $(0 \%, 12.5 \%$ and $25 \%$ polluted soil) along a gradient ranging from 0 to $25 \%$ of polluted soil, set up as in Gradient 2 ( $n=10$ replicates). Individuals were VIE tagged ( 2 weeks prior to use), with a specific colour (blue $(0 \%)$, red $(12.5 \%)$ or yellow $(25 \%))$ to distinguish introduction point into the gradient. For the first $24 \mathrm{~h}$, plastic spacers separating the soil divisions were left in place, to encourage earthworms to burrow into the soil at point of introduction. The final location of each earthworm and colour of VIE tag was recorded. Individual earthworm biomass was also recorded at both the outset and end of the experiment.

\subsection{Statistical Analysis}


186

In gradient 3, differences in biomass associated with point of inoculation were statistically analysed using one-way ANOVA followed by a Tukey multiple comparison test. Each division (pollution level) in gradient 3 was coded $(25 \%=5,18.75=4,12.5 \%=3,6.25 \%=2$ and $0 \%=1)$ and these used to record retrieval point. These data were then analysed using a non-parametric Kruskal Wallis significance test to establish the influence of introduction point on retrieval point across the pollution gradient. Where earthworms were cut by the spacer, an intermediate code was assigned (e.g. 3.5). All statistical analyses were undertaken using Minitab version 16.1 software.

\subsection{Results}

\subsection{Gradient 1}

On introduction on to the soil surface of the $100 \%$ polluted soil 2 O. cyaneum and 4 L. rubellus burrowed down and all others ( 3 O. cyaneum and 1 L. rubellus) burrowed into the adjacent $75 \%$ polluted soil. On destructive sampling after 1 week, all $O$. cyaneum $(n=5)$ and $3 L$. rubellus were located in the unpolluted soil (0\%). Two L. rubellus were not located and were considered to have died during the experimental period. As all surviving earthworms were found in unpolluted soil, this suggested that all levels of polluted soils in the gradient were capable of eliciting an avoidance response and resulted in establishment of Gradient 2, ranging from 0-25\% polluted soil.

\subsection{Gradient 2}

When initially exposed to $25 \%$ polluted soil, 3 O. cyaneum and 5 L. rubellus burrowed down directly and the remainder burrowed into the $18.75 \%$ polluted soil. At the end of the experiment, earthworms were recovered throughout the gradient (Table 1). A 100\% recovery rate was achieved from this experiment with $L$. rubellus present across pollution levels ranging from $6.25-25 \%$. In contrast, $O$. cyaneum were retrieved from unpolluted $(0 \%)$ or $6.25 \%$ polluted soil only.

Table 10 . cyaneum and L.rubellus numbers retrieved from Gradient 2 over a range of pollution levels derived from a contaminated field site in Preston

Soil Pollution levels - earthworm retrieval

\begin{tabular}{lccccc} 
& $25 \%$ & $18.75 \%$ & $12.5 \%$ & $6.25 \%$ & $0 \%$ \\
\hline O. cyaneum & 0 & 0 & 0 & 1 & 4 \\
L. rubellus & 1 & 3 & 0 & 1 & 0
\end{tabular}

\subsection{Gradient 3}

After 7 days of exposure, the majority of earthworms were retrieved from a division of the gradient less polluted than their introduction point, but differences in response between the two species were noted (Table 2). A 100\% earthworm recovery rate was recorded throughout the experiment and all VIE tags remained visible for identification. For earthworms introduced into $25 \%$ polluted soil, $60 \%$ of L. rubellus and $80 \%$ of $O$. cyaneum were retrieved from less polluted soil. For earthworms introduced into $12.5 \%$ polluted soil, $50 \%$ of $L$. rubellus and $100 \%$ of $O$. cyaneum were retrieved from less polluted 
206

soil. However, some earthworms were retrieved from soil with higher pollution levels than their introduction point (Table 2). Introduction point had a significant influence on L. rubellus retrieval point $(p=0.032$ ) but did not significantly $(p=0.343)$ influence retrieval point for $O$. cyaneum with individuals tending to move towards (or remain) in unpolluted soil (average movement $=2.65$ and 1.65 divisions from 25 and $12.5 \%$ introduction points respectively). L. rubellus individuals tended to remain closer to $25 \%$ and $12.5 \%$ introduction points than 0 . cyaneum with average movement away from these points recorded as 1.6 and 1.1 divisions respectively. Movement away from the $0 \%$ introduction point was low for both species ( 0.6 and 0.1 divisions for $L$. rubellus and $O$. cyaneum respectively).

Table 2 O. cyaneum and L.rubellus retrieval rates (\%) from different pollution levels in Gradient 3 with three different introduction points $(25,12.5$ and $0 \%$ polluted soil).

\begin{tabular}{lcccccc} 
& Introduction & \multicolumn{5}{c}{ Soil Pollution levels - earthworm retrieval (\%) } \\
\cline { 2 - 7 } & point & $25 \%$ & $18.75 \%$ & $12.5 \%$ & $6.25 \%$ & $0 \%$ \\
\hline O. cyaneum & $25 \%$ & 20 & 15 & 5 & 0 & 60 \\
& $12.5 \%$ & 0 & 0 & 0 & 35 & 65 \\
& $0 \%$ & 0 & 0 & 0 & 10 & 90 \\
\hline L. rubellus & $25 \%$ & 40 & 10 & 20 & 10 & 20 \\
& $12.5 \%$ & 0 & 10 & 40 & 0 & 50 \\
& $0 \%$ & 0 & 0 & 20 & 10 & 70
\end{tabular}

Changes in earthworm biomass are shown in Table 3. L. rubellus introduced into $25 \%$ polluted soil exhibited decreased mean biomass which was significantly different $(p<0.05)$ from the increased mean biomass recorded for individuals of this species introduced into $12.5 \%$ and $0 \%$ polluted soil. Mean increase in biomass of $O$. cyaneum introduced into 0 and $25 \%$ polluted soil was positive, but was negative for individuals introduced into $12.5 \%$ polluted soil. However, there was a significant difference $(p<0.05)$ between biomass change for individuals of this species introduced into unpolluted soil compared with those introduced into 12.5 and $25 \%$ polluted soil.

Table 3 Mean change in \% biomass for $L$. rubellus and $O$. cyaneum individuals introduced into $25 \%$, $12.5 \%$ and $0 \%$ polluted soil in Gradient 3. For each species, mean values not sharing the same letter were significantly different $(p<0.05)$.

\begin{tabular}{lccc} 
Inoculation point & $\begin{array}{c}\text { Mean change in } \\
\text { Biomass (\%) }\end{array}$ & $\begin{array}{c}\text { Standard Deviation } \\
(\mathrm{SD})\end{array}$ \\
\hline O. cyaneum & & $4.12(\mathrm{~b})$ & 15.45 \\
& $12.5 \%$ & $-0.25(\mathrm{~b})$ & 12.99 \\
& $0 \%$ & $19.05(\mathrm{a})$ & 8.86 \\
\hline L. rubellus & $25 \%$ & $-1.06(\mathrm{~b})$ & 8.92 \\
& $12.5 \%$ & $17.83(\mathrm{a})$ & 11.58 \\
& $0 \%$ & $17.95(\mathrm{a})$ & 8.48
\end{tabular}




\subsection{Discussion}

Results from the first experimental gradient demonstrated a clear avoidance response to the polluted soil with all surviving earthworms retrieved from unpolluted soil. This showed the ability of both species to traverse the length of the experimental container $(0.6 \mathrm{~m})$ during the 7 day period. The minimum percentage level of polluted soil that triggered the avoidance response was established as less than $25 \%$. This led to setting up of Gradient 2 (0-25\%) that allowed for potential differences in species avoidance response to be studied and to further assess the suitability of the linear gradient design as a sub-lethal toxicity test. In Gradient 2, clear differences in retrieval location were recorded after 7 days that suggested a species-specific response to the polluted soil. L. rubellus were retrieved throughout the pollution gradient while $O$. cyaneum were located within to the 0 and $6.25 \%$ divisions. This suggested that (in terms of an avoidance response) 0 . cyaneum is more sensitive to the polluted soil than $L$. rubellus. The tolerance of $L$. rubellus to polluted soils is well documented (e.g. Nahmani et al., 2007; Spurgeon and Hopkin, 1996). Observed differences in avoidance response between the epigeic $L$. rubellus and endogeic $O$. cyaneum support the findings of Lukkari and Haimi (2005) using a two-section avoidance test procedure to establish avoidance responses of three ecologically different earthworm species (L. rubellus, D. octaedra and A. tuberculata) to Cu- and Zn-contaminated soil. $L$. rubellus was found to be the least sensitive species and only responded to the highest metal concentration.

A species-specific response to the pollution gradient was further supported by results from Gradient 3, where identification of individuals with VIE tags allowed earthworms to be simultaneously introduced at 3 pollution levels within the gradient. Findings demonstrated the increased sensitivity of $O$. cyaneum (when compared with L. rubellus) to all levels of polluted soil. Although differences were recorded in retrieval point for 0 . cyaneum introduced at different points along the gradient, these were not significant, with the majority of individuals recorded in $0 \%$ polluted soil. For L. rubellus, significant differences in retrieval point were recorded with individuals generally remaining closer to the point of introduction, which suggests a weaker, or even no, avoidance response. Although results suggest that earthworm movement (dispersal/avoidance) is influenced by the level of pollutants present in the soil, it also has to be recognised that other properties of the polluted soil may have relevance.

Earthworm response to a fixed pollutant level may vary depending on the influence of a range of biotic and abiotic factors and result in a hierarchical response. For example, Fründ et al., (2009) demonstrated that the outcome of a soil preference test in 2D terraria could be reversed by increasing the water holding capacity in one side of the terraria from 70 to $87 \%$. Similarly, species-specific pollutant avoidance behaviour associated within heterogeneous soils may be influenced by availability of / foraging for organic matter (food) (Lowe and Butt, 2002) and the response may have a temporal basis associated with changes in resource availability. Inter-specific and intra-specific interactions (reviewed by Uvarov, 2009) may also influence earthworm position within the soil and so increasing earthworm density in the Gradient 3 design may have influenced retrieval position results. However, it is not possible to determine the influence of these factors on earthworm movement within the experimental design without a method for tracking of individual movement throughout the experimental period. 
Significant differences in change of biomass over the 7 day experimental period were recorded and these were associated with introduction point. However, as suggested by Lowe and Butt (2007) such results should be interpreted with caution given the unknown age and history of the field-collected earthworms used in the study. In contrast, and a significant advantage over other sub-lethal endpoints such as reproduction, the use of field-collected, rather than laboratory-reared, individuals in assessing avoidance is considered valid by the authors with the caveat that individuals for each species used are collected from the same non-polluted location. This further enhances the proposed increased practicality of avoidance tests.

Results have suggested that the use of a linear pollution gradient over a 7 day experimental period may be used to assess earthworm avoidance behaviour in relation to field-collected polluted soil. It is suggested that the gradient system can provide a more ecologically relevant (in terms of the earthworm species used and heterogeneous nature of many polluted soils) alternative to the twosection avoidance test and a more practical alternative to the six-section standardised avoidance test (ISO 17512-1: 2008). However, further work is required to establish the effectiveness of this procedure in initial chemical screening and assessment of single contaminant bioavailability. Therefore future studies may seek to use a single laboratory-reared earthworm species and employ a standardised soil (e.g. OECD artificial soil) with a pollutant gradient established by spiking soils with a single pollutant. This would allow for the uptake of pollutants by earthworms to be measured and directly related to the point of introduction and retrieval. Further research should also seek to compare avoidance response over a range of time periods to establish if this modified avoidance test can provide reliable results comparable with the 48 hours used in standardised tests.

\subsection{References}

Bastardie, F., Capowiez, Y., Dreuzy, J.-R., Cluzeau, D. (2003) X-ray tomographic and hydrolic characterization of burrowing by three earthworm species in repacked soil cores. Appl. Soil Ecol., 24, 3-16.

Bolton, P.J., Phillipson, J. (1976) Burrowing, Feeding, Egestion and Energy Budgets of Allolobophora rosea (Savigny) (Lumbricidae). Oecologia, 23, 225-245.

Butt, K.R., Briones, M.J.I., Lowe, C.N. (2009) Is tagging with visual implant elastomer a reliable technique for marking earthworms? Pesquisa Agropecuária Brasileira, 44, 969-974.

Butt, K.R., Grigoropoulou, N. (2010) Basic Research Tools for Earthworms Ecology. Applied and Environmental Soil Science, 12 pages, available at http://www.hindawi.com/journals/aess/2010/562816/

Butt, K.R., Lowe, C.N. (2007) A viable technique for tagging earthworms using visible implant elastomer. Applied Soil Ecology, 35, 454-457.

Capowiez, Y., Dittbrenner, N., Rault, M., Triebskorn, R., Hedde, M., Mazzia, C. (2010) Earthworm cast production as a new behavioural biomarker for toxicity testing. Environ. Pollut., 158, 388-393.

Dittbrenner, N., Triebskorn, R., Moser, I., Capowiez, Y. (2010) Physiological and behavioural effects of imidacloprid on two ecologically relevant earthworm species (Lumbricus terrestris and Aporrectodea caliginosa). Ecotoxicology, 19, 1567-1573. 
Environment Agency (2008) Using science to create a better place. Guidance on the use of soil screening values in ecological risk assessment. Bristol.

Evans, A.C. (1947) Method of studying the burrowing activity of earthworms. Ann. Mag. Nat. Hist., 11, 643-650.

304

Fründ, H.C., Graefe, U., Tischer, S. (2011) Earthworms as Bioindicators of Soil Quality. Biology of Earthworms (ed. by A. Karaca), pp. 261-278. Springer, London.

Fründ, H.C., Wallrabenstein, H., Leißner, S., Blohm, R. (2009) Developing a soil quality test with 2D terraria and Aporrectodea caliginosa. Workshop Kommission III der Deutschen Bodenkundlichen Gesellschaft “Experimenting with Earthworms" Veranstalter: Kommission III der DBG 20.-21.03.2009, Trier Berichte der DBG (nicht begutachtete online Publikation) http://www.dbges.de

Garcia, M., Römbke, J., de Brito, M.T., Scheffczyk, A. (2008) Effects of three pesticides on the avoidance behaviour of earthworms in laboratory tests performed under temperate and tropical conditions. Environ. Pollut., 153, 450-456.

Glover, A. (2010) Case study for the reduction of waste at a lead contaminated site. School of Built and Natural Environment, University of Central Lancashire, Unpublished MSc thesis.

González, G., Espinosa, E., Liu, Z. \& Zou, X. (2006) A Fluorescent marking and re-count technique using the invasive earthworm, Pontoscolex corethrurus (Annelida: Oligochaeta). Caribbean J. Sci., 42, 371379.

Hund-Rinke, K., Achazi, R., Römbke, J., Warnecke, D. (2003) Avoidance test with Eisenia fetida as indicator for the habitat function of soils: Results of a laboratory comparison test. J. Soils Sediments, 3, 7_12.

ISO 17512-1 (2008) Soil quality - avoidance test for determining the quality of soils and effects of chemicals on behaviour - Part 1: test with earthworms (Eisenia fetida and Eisenia andrei). ISO (International Organization for Standardization), Geneva.

Jones, C.G., Lawton, J.H., Shachak, M. (1994) Organisms as ecosystem engineers. Oikos, 69, 373-386. Jouquet, P., Dauber, J., Lagerlöf, J., Lavelle, P. \& Lepage, M. (2006) Soil invertebrates as ecosystem engineers: Intended and accidental effects on soil and feedback loops. Appl. Soil Ecol., 32, $153-164$.

Langdon, C.J., Piearce, T.G., Meharg, A.A., Semple. K.T. (2003) Inherited resistance to arsenate toxicity in two populations of Lumbricus rubellus, Environ. Toxicol. Chem., 22, 2344-2348.

Lowe, C.N., Butt, K.R. (2002) Influence of organic matter position on earthworm production and behaviour: A laboratory-based approach with applications for soil restoration. Eur. J. Soil. Biol. 38, 173176.

Lowe, C.N., Butt, K.R. (2005) Culture techniques for soil dwelling earthworms: a review, Pedobiologia, 49 (5), 401-413.

Lowe, C.N., Butt, K.R. (2007) Earthworm culture, maintenance and species selection in chronic ecotoxicological studies: A critical review. Eur. J. Soil Biol., 43, S281-S288. 
Lukkari, T., Aatsinki, M., Väisänen, A., Haimi, J. (2005) Toxicity of copper and zinc assessed with three different earthworm tests. Appl. Soil Ecol., 30, 133-146.

Lukkari, T., Haimi, J. (2005) Avoidance of Cu- and Zn-contaminated soil by three ecologically different earthworm species. Ecotox. Environ. Safe., 62, 35-41.

Ma, W.C., Bonten, L.T.C. (2011) Bioavailability pathways underlying zinc-induced avoidance behaviour and reproduction toxicity in Lumbricus rubellus earthworms. Ecotox. Environ. Safe., 74, 1721-1726.

Morgan, J.E., Morgan, A.J. (1999) The accumulation of metals ( $\mathrm{Cd}, \mathrm{Cu}, \mathrm{Pb}, \mathrm{Zn}$ and $\mathrm{Ca}$ ) by two ecologically contrasting earthworm species (Lumbricus rubellus and Aporrectodea caliginosa): implications for ecotoxicological testing. Appl. Soil Ecol., 13, 9-20.

Nahmani, J., Hodson, M.E., Black, S. (2007) A review of studies performed to assess metal uptake by earthworms. Environ.Pollut., 145, 402-424.

347 Naidu, R. Bolan, N.S., Megaharaj, M., Juhasz, A.L., Gupta, S.K., Clothier, B.E., Schulin, R. (eds.) (2008)

348 Chemical Bioavailability in Terrestrial Environments. Developments in Soil Science Volume 32. Elsevier.

349 Owojori, O.J., Reinecke, A.J. (2009) Avoidance behaviour of two eco-physiologically different 350 earthworms (Eisenia fetida and Aporrectodea caliginosa) in natural and artificial saline soils. 351 Chemosphere, 75, 279-283.

Smith, R., Pollard, S.J.T., Weeks, J.M., Nathanail, C.P. (2006) Assessing significant harm to terrestrial ecosystems from contaminated land. Soil Use Manage., 21, 527-540.

Spurgeon, D.J., Hopkin, S.P. (1996) The effect of metal contamination on earthworm populations around a smelting works: quantifying species effects. Appl. Soil Ecol., 4, 147-160. (Lumbricus rubellus) to copper and cadmium as determined by measurement of juvenile traits in a specifically designed test system. Ecotox. Environ. Safe., 57, 54-64. characteristics of Lumbricus terrestris and effects of the veterinary antiparasitic compounds ivermectin and fenbendazole. Soil Biol. Biochem., 37 927-936.

362 Uvarov, A.V. (2009) Inter- and intraspecific interactions in lumbricid earthworms: Their role for earthworm performance and ecosystem functioning. Pedobiologia, 53, 1-27. 296. 